\title{
Home and school literacy practices of children attending Malayalam classes in Singapore
}

\author{
Suvita Thanagopalasamy \\ suvita12@gmail.com \\ Singapore University of Social Sciences
}

Anitha Devi Pillai

anitha.pillai@nie.edu.sg

National Institute of Education,

Nanyang Technological University, Singapore.

\begin{abstract}
The Malayalee community, a minority language group in Singapore, lacks institutional support for learning their mother tongue in schools. In school, most Malayalee children opt to study Tamil or Hindi, a Non-Tamil Indian Language (NTIL) in place of Malayalam. Over the years, ground-up initiatives by volunteers have resulted in ad-hoc community-run classes which are conducted by volunteers. In 2010, a community-run initiative, Organization $X$, was set up to formalize the learning and teaching of Malayalam in Singapore. This paper aims to investigate the home and school literacy practices of the children enrolled in the Malayalam classes at Organization $X$ with a view to understand the impact of these lessons on the community. The study found that when both home and school literacy practices were viewed as social activities, it contributed to the maintenance of the language in the community.
\end{abstract}

Keywords: Language maintenance, home and school literacy practices, Malayalam 


\section{Introduction}

Mother tongue language maintenance of minority languages requires an ideological commitment from the family and community, especially in the face of competing dominant languages such as English as well as other societal demands. At home, often migrant families may not necessarily be able to transmit the language to the next generation despite their best intentions and desire to do so. For instance, in the case of Sri Lankan Tamils in Canada, the UK and USA (Canagarajah, 2008), parents opted to send their children to community-run classes on culture and arts rather than language. In a study of the Turkish migrant community in the Netherlands, Sevinc (2016) revealed that parents' academic expectations for their children and lack of use and reading materials in their homes led to a gradual decrease in the next generation being literate in Turkish. The Korean American community too were found to not use their mother tongue at home at all times despite their desire to do so with their children (Kang, 2015). At the grassroots level, the American Korean and Cambodian communities in Lee and Wright's (2014) study did exhibit a strong commitment to transmitting their mother tongue languages to the next generation through the language classes that they organized. However the study did not examine the home literacy practices of the students who attended the community-run classes. An examination of these two components, home and community-run school literacy practices, will provide an insight into language use and maintenance patterns in the community.

Similar to the Lee and Wright's (2014) study, in Singapore, the Malayalee community has organized Malayalam language classes to transmit their mother tongue to the next generation and promotes literacy in their mother tongue through online publications such as Pravasi Express (a bilingual Malayalam newspaper) and Ithalukal (a Malayalam magazine). There are 26,541 reported speakers of the language in Singapore (Department of Statistics Singapore, 2015) which makes them the second largest ethnic group within the Indian community in the country, after the Tamils. The formation of Malayalam classes. in particular, indicates that as a community there is a heavy emphasis on learning one's mother tongue especially since Malayalam is not one of the languages formally taught in schools in Singapore (Moore, 1994).

According to the Mother Tongue Language Policy in Singapore (MOE, 2015), a non-Tamil student such as a Malayalee is only allowed to take Tamil or a Non-Tamil Indian Language (NTIL) such as Bengali, Gujarati, Hindi, Punjabi or Urdu as his 'mother tongue'. Malayalee children are hence assimilated into the Tamil community or one other Indian community, whose languages are 
distinctively different from Malayalam (Sridhar, 1995), and the children grow up with limited access to the learning of this language (Pillai, 2010). Not surprisingly, previous studies (Anandan, 1996; Fernandaz, 1998; Pillai, 2010) have identified the lack of institutional support as the main factor contributing to language shift in this community.

Nevertheless, despite the lack of state support and access to Malayalam, it is important to note that the literacy practices of the language have not become obsolete in Singapore. On the contrary, as a response to the community's language shift, there is concerted effort in place to maintain and transmit the language to the next generation. In 2010, Organization $X^{1}$, an organization that provides community support in Malayalam language learning, was formed by a group of volunteers with the main goal of promoting learning of Malayalam in Singapore and to eventually gain MOE's recognition of Malayalam as a second language. It is currently the largest and most prominent organization involved in the teaching of Malayalam, with eight regional centres across the island. The current research considers the presence of Organization $X$ as an important factor in the language maintenance of Malayalam in Singapore. None of the previous studies have examined the impact of Organization $X$ on language maintenance.

To date, four key studies have examined the language use of the Malayalee community in Singapore. Anandan (1996) focused on the language use of Hindu Malayalee families at home in Singapore and reported a language shift of Malayalam to English, particularly among the young Malayalees. Fernandaz (1998) confirmed Anandan's findings in a similar study that looked into the Christian Malayalee community and further concluded that religion was not an important factor that supported language maintenance amongst the Malayalees in Singapore. Ten years later, Pillai's (2010) study focused on the use of Malayalam as a spoken language at home and examined the language choices and speech patterns present in the language. Unlike the previous two studies, she concluded that there was not necessarily any language loss of Malayalam in Singapore. Instead, she revealed a particular hybrid variety of Singapore Malayalam, spoken by second and third generation Malayalees, indicating the presence of several other factors involved in the evolution of the language. As the statistics on its community residents for the last two generations are not publicly available, and that the three studies (Anandan, 1996, Fernandez, 1998 and Pillai, 2010) were qualitative studies, it is not possible to determine the ratio of speakers of this hybrid variety of speakers.

\footnotetext{
${ }^{1}$ Name of organization has been anonymized upon the request of the interviewees.
} 
In her later study, Pillai (2017) described the language revival efforts made by the community through language education classes, the presence of the Internet that provided more opportunities for exposure to the language, the greater ease of travel to Kerala for families to keep in touch with their relatives in their homeland as well as the presence of Asianet (a Malayalam channel from India) in 2005 as pivotal in reviving the language use in the community. None of the four studies, however, investigated the literacy practices of the children who attended Organization $X$ 's classes, which is the focus of this current study.

Given that language maintenance amongst migrant and minority groups is boosted when members are literate in the language (Gibbons \& Ramirez, 2004), it is worthwhile to explore the literacy practices of the community whose children attend classes at Organization X. As such, this article addresses the following research questions:

- Do the classroom (Organization X) literacy practices of the Malayalee students help with the maintenance of the language?

- Do the home literacy practices of the Malayalee students and their parents help with the maintenance of the language?

\section{Literature Review}

This section will examine literacy practices and events as social activities and investigate the relevance of school and home literacy practices to the maintenance of a minority language.

Barton (2007) argues that literacy should be understood as a social activity that is shaped by people's literacy practices in the various literacy events they take part in. He describes these literacy events as "occasions in life where the written word has a role" and emphasizes the importance of such literacy events in the children's learning of a language (Barton, 2007, p.35). The current research will adopt this view and definition of literacy when investigating the Organization $X$ students' literacy practices. Although the Malayalees form a significant part of the Indian community in Singapore, with the lack of government support, access to the formal learning of Malayalam is limited to Organization X, which has surfaced as a community effort. The idea that literacy is a social activity influenced and shaped by the larger society is evident here. While there are several social factors involved in the shaping of literacy learning, the domains of school and home literacy play an essential role in the lives of children learning Malayalam and will hence 
be further examined in the current research in the context of language maintenance of a minority language.

Language maintenance refers to the continuing usage of one language or more than one language in the midst of competition from one or more regionally and socially more powerful languages (Mesthrie, Swann, Deumert \& Leap, 2013). In the context of Singapore, Malayalam can be said to face competition from Tamil, the official Indian language designated by the government and hence often used in schools as a mother tongue language. Nevertheless, while Malayalam is considered a minority language in Singapore, the continuing presence and use of the language, found in the various Malayalee organizations as well as Organization $X$, denote a degree of language maintenance. While there are several elements such as economic factors, demographic factors, institutional support and language status playing important roles in language maintenance (Mesthrie, Swann, Deumert \& Leap, 2013), in this current research, the contributing factors of school and home literacy are examined in the context of children attending Malayalam classes to explore how these have been crucial in the maintenance of the language.

\subsection{Home Literacy}

The home environment is seen as an important aspect of a child's learning and acquisition of language literacy. Early language literacy can be seen as embedded in the social interactions surrounding a child (Barton, 2007). Since the home is the first and most important institution in a child's life, its importance cannot be overstated. Home literacy practices and events refer to factors such as dominant language use at home, storytelling and reading of books as well as media such as TV and Internet. In the context of Malayalam home literacy practices, these may refer to home practices such as speaking in Malayalam or reading books in Malayalam.

While there may be various other factors influencing the language maintenance of a minority language, the home environment and home literacy practices and events are seen as especially important in language maintenance. In fact, it has been argued that the one factor that can be identified with certainty to be of crucial importance for language maintenance is linguistic transmission from one generation to another (Saarikivi \& Marten, 2012). This 'linguistic transmission from one generation to another' is most evident in the home environment where parents transmit the language to their children, allowing language maintenance. 
Moreover, studies of literacy practices have revealed that there is a close relationship between school and home literacy practices, where learning in school was highly dependent on home literacy practices. Koh's (2010) study of young Chinese children's literacy learning in Singapore revealed that literacy strategies employed by the parents played a crucial role in the preparation of the children's academic performance in school. Home literacy practices such as the dominant home language was important in shaping the child's learning in school. Balakrishnan's (2001) study on the English and Tamil literacy practices of Indian families in Singapore; found that the home environment was essential in supporting the literacy abilities of the children in the classroom. The parents in her study were largely motivated by the desire for their children to perform well in the school and hence constructed a rich literacy environment in the home, facilitating the formal learning in school. This particular motivating factor linked to school success cannot be applied to Malayalee families since Malayalam is a non-school subject. However, it would be interesting to see if the conclusion that the home is an essential aspect of literacy could still hold true. Moreover, the notion of a literacy rich home environment facilitating formal learning in school supports the current research's hypothesis that Malayalam as a minority language is, in part, maintained through home literacy practices.

\subsection{School Literacy}

Schools have a strong association with the learning of literacy since these institutions exist for the main purpose of teaching children. In Singapore, literacy is closely associated with doing well in school and is often thought of as a set of skills to be mastered (Barton, 2007). The case of Malayalam literacy however is unique as it is not included in the mainstream school education system and is a non-examinable subject. Nevertheless, efforts by Organization $X$ to align the syllabus of the Malayalam classes to standards of other Non-Tamil Indian languages from the Board for the Teaching and Testing of South Asian Languages (BTTSAL) illustrate the centre's commitment in establishing a formal education system (Vasnani, 2014). Therefore, the current research will study the literacy practices of Organization X's on a par with those of other schools. According to Barton (2007), schools form a significant reference point for children learning a language. School literacy practices and events refer to the activities that take place in the classroom. In the context of the children learning Malayalam in Organization $X$, the literacy 
practices in the classroom may refer to official activities such as reading and writing tasks as well as unofficial activities such as interactions with other children in Malayalam.

\section{Methodology}

This section describes in detail the research participants as well as the various research tools and methods that were used to investigate the home and school literacy practices and events of Organization $X$ 's students involved in the current research. The following research methodology is primarily qualitative and was designed to be holistic in the collection of data, allowing the researchers to uncover the various underlying social factors that are intertwined with literacy practices and the maintenance of a minority language. All the names of the interviewees have been anonymized at the request of the interviewees. Likewise, the name of the centre too is anonymized and referred to as Organization $X$ in this paper.

The current research has Organization $X$ as the main point of research enquiry and investigated the home and school literacy practices of the children attending Organization $X$ 's classes to learn Malayalam by interviewing their parents and making visits to their homes. The main goal of sampling a relatively small number of participants, in a qualitative research study, is to ensure that the research yields data that is saturated and rich (Dörnyei, 2007).

Ten families were selected through convenience sampling out of those who volunteered to participate in the study. Nine out of ten families were new migrants having arrived in Singapore as adults from India. The selected parents had children who were in pre-primary to lower primary school to reflect the focus on young children learning Malayalam.

In this research, parental involvement is recognized as a key factor in the children's learning of the Malayalam language and is seen to contribute to language maintenance. While the research focused on the students' literacy practices, their parents also participated in the research since an inquiry into the students' family literacy practices was essential to this study. In this instance, parental involvement includes the child's enrollment at Organization $X$ as well as other Malayalam literacy practices that took place in the home environment. Moreover, due to ethical considerations and the sensitivity involved in working with the children directly, most of the information concerning their literacy practices was sought from the parents to provide a holistic view on the various factors shaping their children's literacy practices. 
A third-generation Singaporean parent, Ms Stella, who had recently stopped sending her children to Organization $X$, was also included. Her family provided the chance for opportunistic sampling and allowed the researchers to explore this case as a deviant case sampling. With a deviant case sampling, the researchers selected an extreme case with a markedly different form of experience from the other selected cases allowing them to underscore commonalities across the participants and explore the limits of the findings indicated by the rest of the participants (Dornyei, 2009). Despite the best attempts of the researchers, it was not possible to identify second or third generation Singaporean families whose children attended classes at Organization $X$, to be part of this study.

Three key personnel involved in the founding and running of Organization $X$ were included in the research to provide crucial background information on the Malayalam language centre. Interviews with the key personnel were necessary to provide the researchers with crucial background information about the centre and to know more about its role in Malayalam language maintenance.

\subsection{Data Collection}

Research data from the participants was collected through observations and interviews. The methodology of observation was central to this research. Observation of the participants would provide the researchers with direct information rather that self-reported data (Dornyei, 2009), increasing the reliability of the data collected. Since the focus of this research was on both the school and home literacy events of the participants, observation was key in both of these environments.

In observing the participants in the school environment, the researchers sat at the back of the Organization $X$ class and observed the participants' literacy practices in it. Observation of an Organization $X$ school event was also carried out. As the Organization $X$ school environment would be familiar to the participants, the likelihood of observing the students where they are comfortable would increase and allow the data to show representative behaviour (Wray \& Bloomer, 2012). The researchers were also able to obtain non-elicited data since the school activities were not controlled by the researchers. The observation conducted in the classroom, while mostly structured to facilitate the research purpose, included some flexibility to allow the 
researchers to take down notes on observations that may be significant to the study. The observation of the school event was designed to be more flexible and freer.

Observation of the children and their families' literacy practices in the home environment was also conducted to allow the researchers to understand the role of home literacy in the participants' lives and in the maintenance of language. A total of ten observations of the home literacy practices were conducted, with one home observation for each child. The researchers observed literacy practices in the household as well as literacy artefacts surrounding the home. With the permission of the parents, photographs of Malayalam literacy artefacts in the home were also taken.

In early studies on the use of Malayalam in Singapore, Anandan (1996) and Fernandaz (1998) had collected their research data from participants solely through interviews and other selfreported methods such as surveys. The researchers were hence only given access to what the participants were willing to share with them about their language use. The current research sought to overcome this limitation through the added methodology of observation to minimize the use of self-reported data from participants.

\subsection{Interviews}

Interviews were conducted with the children's parents to allow the researchers to obtain detailed descriptions of the world that the interviewees inhabited with respect to the literacy practices the children and their families engaged in. Since it would be difficult to observe every single literacy practice of the participants, the interviews were useful in eliciting more information. The parents of Organization X's students were interviewed in their homes, and done along with the home observation. With semi-structured interviews, the researchers had provided the parents with guiding questions while keeping the questions open-ended. The use of semi-structured interviews would encourage participants to elaborate on the literacy practices of their home and children and discuss issues raised in an exploratory manner (Dornyei, 2009).

Semi-structured interviews were also conducted with key personnel behind Organization $\mathrm{X}$, such as one its founders and the general secretary of the organization. Since the current research focuses on its students, interviewing the people behind this centre provided the researchers with important information regarding the centre's operation and goals. The interviews were also important in looking at the role of the centre in language maintenance. 
While the research conducted is largely qualitative in its collection of data, a quantitative data analysis method, data coding, was used to analyze the interviews conducted. Here, data coding refers to the conversion of the research interviewees' responses to statistical representation through means of 'coding procedures' (Dornyei, 2009). Data coding forms an essential part of data analysis process and allows the researcher to highlight common themes, ideas and beliefs emerging from the various interviews. In analyzing the findings, themes such as positive attitude, dominant language, reading Malayalam, presence of Malayalam artefacts and media were surfaced. These common threads were then organized into different categories and analyzed in the context of the current research question.

\section{Results and Discussion}

The findings revealed that there was strong community support for Organization $X$ from the larger Malayalee community and amongst the interviewees as all the families were actively involved in the cultural programmes organized by Organization $X$. This included the third-generation Singaporean parent, Ms Stella, in this study.

\subsection{Strong Community Support}

The interviews with the key personnel involved in the formation of Organization $X$ revealed that there was strong community support for the organization. For instance, the organization's founding members are notable community leaders and they attend as many of the organization's events as they can.

The interviewees described their organization as a ground-up initiative that began with a group of Malayalee parents, both new migrants and local Singaporeans, who wanted their children to learn Malayalam. It was the effort of these parents from the community that eventually led to the formation of the organization. Organization $X$ was started with the primary aim of promoting and teaching Malayalam and is not driven by profits. As such, it is run largely by volunteers. At the point of this study, the teachers were paid an honorarium of fifteen Singapore dollars per hour.

The support that Organization $X$ has been receiving from the community cannot be overstated. The volunteers, parents and community leaders are an important part of Organization $X$. Their support has allowed the formal teaching of Malayalam in Singapore, giving Malayalees an opportunity to learn the language. The community's support that is given to Organization $X$ 
indicates that Malayalam literacy is seen as a social activity that is of vital importance to the community, ensuring language maintenance of Malayalam.

\subsection{Parental involvement and attitude}

As part of the observation of school literacy activities, the researchers attended Organization X's annual school event. The event showcased the talents of Organization X's students and parents through a series of literacy competitions that included poem recitation, singing and story telling.

Observation of the literary competitions revealed that many students had a high level of Malayalam language proficiency and performed well in the various categories. Parents of Organization $X$ 's students also took part in a category allocated to them, reciting poems. It was observed that Mr Mohan, one of the parents who were involved in this research study, took part in the competition as well. Support from the community for this event was observed to be strong, with the entire school hall being filled with parents, friends and family.

The observation at the cultural event is further supported by the findings of the interviews with parents that were conducted before the event. During the interviews with parents, most of them described in detail the cultural events of Organization X as part of their children's Malayalam language education. Many parents also shared that they would help their children prepare for the cultural event by picking out poems and helping their children rehearse for it. For instance, Ms Anu, a parent, told the researchers that she would help her daughter, Nandhini, prepare for the event by teaching her to recite poems. Her daughter won the third prize for poem recitation one year. The following year, Nandhini chose a slightly longer and more difficult poem. During the competition, Nandhini had forgotten a couple of lines during the competition and was very disappointed at not having won anything. Ms Anu told the researchers that she and her daughter had been preparing for the upcoming cultural event for a few months. Another parent, Ms Lorraine, had also told the researchers during the interview that her daughter Jennifer had competed in the event in the previous two years and had won the first and second prize respectively. Ms Lorraine too indicated supporting Jennifer and helping her prepare for the events.

It was clear that not only were parents highly supportive of Organization $X$ and its activities, but they perceived these activities as a social event for the Malayalee community. Even Ms Stella reported having attended the events with her family when her children were enrolled in Malayalam classes. Unlike regular school events that are commonly only open to students in a 
much more formal setting, this event embodies a carnival-like community spirit. During the event, it was observed that there was a sense of familiarity amongst all the participants making it look more like a family event. The strong parental and community support and participation by parents and extended family during school events organized to promote the language, shows that they perceive language maintenance as a social and cultural activity and not one that was relegated to the classroom alone.

It was evident that the community and the families of the students enrolled in Organization $X$ had a positive attitude towards language maintenance. One of the parents, Mr Jitesh shared that tutors in Organization $X$ were instructed to make lessons fun by introducing more songs and poetry into the lesson plans. In fact, it was observed by the researchers that the second half of Organization $X$ 's classes generally include games and rhymes to teach the language. The centre also made use of cultural celebrations such as Onam and Vishu to transmit cultural values to the children. By relating literacy learning to celebrations occurring in the community, literacy was associated with social activities and fun that bonded the community together. The students were thus encouraged to learn the language because of its relevance. Organization $X$ 's positive attitude towards Malayalam is embodied in the concluding remarks made by Mr Jitesh, a key figure in Organization $X$, during the interview:

As long as Malayalam is offered as a language (in community-run classes like Organization $X$ ) and as long as tutors offer their services, the language (Malayalam) would survive.

\subsection{Home Literacy}

In exploring the home literacy practices and events of Organization X's students and their parents, parental support and a literacy rich home environment emerged as key conditions for language maintenance.

The researchers found that there was strong parental support within the home environment for their children's Malayalam literacy practices. These served to provide the children with the conducive environment, encouragement and support required to facilitate their language learning allowing the maintenance of language. During interviews conducted with the parents sending their 
children to Organization $X$, all ten parents reported Malayalam was their dominant language and that they made a conscious effort to speak Malayalam at home.

Mr Mohan, a father of two sons in primary school, emphasized that his family made a deliberate decision to speak in Malayalam at home as he wanted his children to be conversant in the language and subsequently communicate with his family in India. He believed that it was important to use Malayalam as the home language as it is the only place where children can be exposured to the language as shown in the quotation below:

... most of these Malayalee parents, they start speaking in English so that kids would not face any problems in school or outside. We stopped that because we know that anyway kids would learn English in school... The only place they can learn Malayalam is at our home. And if we stop speaking Malayalam, then that's all... end of it. If we go back for vacation (to Kerala) or something, they would not understand... even amongst cousins they would not be able to interact.

He shared that his older son was coping well with the lessons at Organization X which he had been attending for the last five years. Likewise, another parent, Ms Serene, said that she only spoke in Malayalam at home. She explained that if she heard her children speak in English at home, she would ask them to speak in Malayalam instead. Her son learnt to read and write in Malayalam in just four months of attending Organization X. All 10 parents also said that they only spoke in Malayalam when interacting with other members of the Malayalee community.

Since literacy is embedded in the oral interactions surrounding a child (Barton, 2007), the use of Malayalam as the main language in the home environment exposes the child to the language and is important in his/her acquisition of literacy practices. In each of these cases, it can be observed that the parents' use of Malayalam as the dominant language ensures that the child grows up speaking fluently in Malayalam, contributing to the child's ability to do well in Organization $X$ 's classes. Here, linguistic transmission from the parents to their children ensures language maintenance. Moreover, the use of Malayalam as the dominant language in the home and with others in the community, supports the notion of literacy as a social activity that contributes to the maintenance of language.

Here, it must be noted that the third-generation Singaporean parent, Ms Stella, was the only one who had reported that her dominant language was English. She also explained that her children were unable to speak in Malayalam and added that interactions with relatives were in English. 
Once her children stopped attending Malayalam classes at Organization X, Malayalam, it ceased to be a social activity, removing the need for literacy and maintenance of the language.

Moreover, given the vast difference in the numbers of Tamils $(192,665$, Department of Statistics, 2015), and Malayalees in Singapore, one would think that Tamil may be cited as a competing language to Malayalam among the community. However, none of the Malayalee parents thought of Tamil as a competing language in their homes. Most of the parents interviewed had chosen to enroll their children in Hindi classes, a mother-tongue in lieu language rather than in Tamil, the official Indian language in Singapore that is taught in the mainstream schools.

Interviews with the parents also revealed a positive attitude towards the language and this could be seen as the reason that they were motivated to send their children to Organization X. All ten parents felt strongly about Malayalam and displayed a positive attitude towards it. The parents spoke of their love for the language, the cultural value it has, and the rich literature it contains. The positive attitude that the parents displayed will likely influence the way their children consider the language. Growing up in a home environment where their mother tongue is considered with much loyalty and love, the children's attitude towards the language is likely to be shaped positively from a young age. A positive attitude towards the language would encourage children to learn with motivation and be better performers in school, enabling language maintenance. Moreover, when all the parents interviewed were asked whether it was important that their children scored well in Organization $X$ 's class assessments they responded that that was not important. They all concurred that the objective was for their children to be literate and proficient in Malayalam and made no attempt to pressurize their children to excel in Malayalam class.

While the students were generally not given work to do at home, all parents said that they would help their children with Malayalam homework if they had any. One parent, Ms Lorraine, said that she would allocate a part of Friday evenings to revise Malayalam school work from Organization $\mathrm{X}$ with her child. The literacy practices in the home thus help to ensure that the child does well in the classroom. On the other hand, Ms Stella reported that she did not do this because she was not proficient in written Malayalam herself but she encouraged her children to review the lessons on their own. 


\subsection{A Literacy Rich Home Environment}

During the interviews with the parents and home observations, it was found that all ten homes had a rich literacy environment that was further supported by the various literacy practices that the parents participated in. These situated literacy practices in social activities set in everyday lives.

Reading in Malayalam in the home was a factor that was common among all the ten parents and one of the most prominent literacy practices. Artefacts such as Malayalam storybooks, calendars, religious texts such as the Bagavad Gita and the Bible, textbooks, newspapers and magazines were observed in these homes. All the parents from the ten families reported reading Malayalam newspapers daily or weekly such as the Mathrubhuni, Malayala Manorama and Pravasi Express. Parents such as Mr Jayram said that they would read at least two to three online Malayalam newspapers daily. Some parents were also avid Malayalam book readers and had a collection of Malayalam books at home. Mr Kathir, for instance, has a huge collection of Malayalam books in his living room. He regularly read online Malayalam newspapers and subscribes to Bhashaposhini, a magazine catering to readers interested in serious Malayalam literature.

Another parent, Mr Sachin, an editor of a Malayalam magazine and author of several Malayalam books, was an avid reader with a huge collection of books in his home quoted a wellknown Malayalam quotation about the importance of reading to explain his wide collection of books at home:

If you read, you will grow. If you do not read, still you will grow... But only if you read, you will flourish and grow well otherwise you will grow... but you will grow like a tree that is bending down to the ground... to me all those books are our wealth.

Others such as Ms Pushpa and Ms Padma said that they would read Malayalam magazines frequently. Thus, all parents sending their children to Organization X's classes not only provide a rich literacy environment for their children, but also participate in daily Malayalam literacy activities in the home. Malayalam literacy practices could be seen as social activities that they take part in in their everyday lives. The children in these families are hence constantly surrounded by a wide variety of Malayalam literacy artefacts and exposed to literacy practices from a young age. The children would thus be used to the notion of Malayalam literacy and possibly believe that Malayalam literacy learning was only a natural next step for them and a way to enter the adult world. This would have a positive effect on their own literacy learning in both the home and 
Organization $X$ 's environment, as the children would be able to perform better as motivated learners.

\subsection{Malayalam TV Channel and Malayalam Movies}

During the interviews and home observation, the researchers found that Malayalam TV shows and movies were a part of most of the families' leisure time. Many parents said that they would, as a family, watch Malayalam TV programs and movies in the cinema. In particular, the Malayalam TV channel, Asianet was subscribed to by all homes of the parents in this study. Malayalam TV shows and movies have been useful in transmitting the Malayalam language to the children.

A parent, Mrs Jaishri, said that her daughter tries reading Malayalam movie titles and subtitles on the TV to improve her literacy skills. In fact, the presence of a Malayalam TV channel, Asianet, was the one and only common Malayalam resource found in the home of the Ms Stella. Ms Stella had said that her husband regularly watches a spiritual programme on Asianet, while she would occasionally watch Malayalam movies on that channel.

Mr Kathir had incidentally been a member of the team involved in getting Asianet to Singapore. He explained that Asianet was brought to Singapore 10 years ago, because at that point in time, as he described it, there was a lack of Malayalam movies and TV shows for Malayalees in Singapore to enjoy and gain greater exposure to the language as shown in the quote below:

If you look at some of the second-generation Singaporeans, they had almost completely lost touch with the Malayalam. I believe it's mainly because there was no usage of Malayalam at that time...there were not many movies not much Malayalam things to enjoy and stuff like that. I think entertainment helps people learn the language... TV seems to be a huge influence in that area and if you see in the last probably 10 years, there is a big improvement on even the secondgeneration people watching Malayalam and then trying to understand more.

Greater access to Malayalam entertainment helped to revive the language as people are drawn to entertainment rather than books. As Mr Kathir explained even his own daughter preferred watching the epic Ramayana to reading it.

The problem is I think nobody wants to read because these things are easily available more in visual forms right. It is easier to see Ramayana in animated story than read it. So, nobody wants to read it.

The notion that the media is capable of transmitting language and contributing to language maintenance is apparent here. But whilst it helped to keep the language alive and provided some 
exposure to the alphabet, it contributed minimally to ensuring the next generation was literate in the language.

Having a rich Malayalam literacy environment indicates the role of literacy as a social activity that is seen in the daily activities and interactions of the community, including the family and home. The home environment plays an essential role in the learning that takes place in the school. The students of Organization $X$, having been surrounded by a variety of Malayalam artefacts, are likely to perform well in school. Malayalam literacy then continues to be a part of their lives, contributing to the language maintenance.

\section{Conclusion}

The findings gathered in the research conclude that both classroom (Organization $X$ ) and home literacy practices contribute significantly to the maintenance of Malayalam in Singapore. The Malayalee community views literacy as a social activity in both the school and home environments. Malayalam is the primary mode of language used in interactions with family and friends in the community. The home is seen as the first and most important social institution and Malayalam literacy begins there with the support of the parents. The community-run school, Organization $X$, is also seen as an extension of the larger community. Language is maintained by viewing literacy as a social activity that bond and connect individuals to the larger community.

In the Organization X's school environment, Malayalam literacy practices and learning takes place within a supportive context, with a positive approach towards the teaching of the language and the presence of a strong community support for Organization $X$ 's classes and its school events. Malayalam literacy is seen as a social activity that brings members of the community together. Here, Organization $X$ becomes a community that ensures language maintenance.

In the home environment, the students and their parents were observed to be surrounded by a rich variety of Malayalam literacy artefacts such as books, magazines, newspapers and religious texts. The students' literacy experience was further enabled by supportive parental involvement that included speaking Malayalam as the dominant language in the home, reading Malayalam books or newspapers daily and having an overall positive attitude towards the language. The presence of such strong support for the Malayalam language and literacy practices within the home domain, despite a lack of institutional support and mainstream school relevance, 
indicates that the Malayalee community is able to look beyond these factors. The language is viewed as a social element that is used in everyday interactions and activities within the community, ensuring language maintenance. Further research with a larger sample size needs to be undertaken to study home literacy practices of third or fourth-generations families like that of Ms Stella, who showed a keen interest for their children to be literate in the language, but were not necessarily sending their children to Organization X's classes.

The current research found that Malayalam literacy practices, present in both home and school were viewed as a social activity in the community which allowed for language to be maintained in the community.

It is important to compare the findings of this study with how the social construct of Malayalees in Singapore has changed since the 1990s when Anandan (1996) and Fernandez (1998) strongly suggested that without any intervention, the community was likely to end up being not proficient in Malayalam in the future. Organization X's intervention in the recent years might have served to address this. Furthermore, with the influx of migrants in recent years, there is a significant growth in resident population of first generation Malayalees from India residing in Singapore now as compared to during the 1990s. The community, in fact, doubled from 12,451 in 1980 (Khoo, 1981), 16,329 in 1990 (Lau, 1992), to 26,541 in 2015 (Department of Statistics, 2015) resulting in

almost half of the Malayalee resident population (since 1980) being first-generation speakers of Malayalam. It will be worthwhile to analyze the impact of the rise in the population of Malayalam speakers and the resulting community literacy practices to see if this has an impact on language maintenance of third or fourth-generation Malayalees in the future.

\section{References}

Anandan, S. (1996). Language Use Patterns of Malayalees with Three-Generations in Singapore. Unpublished Master of Arts Thesis, National University of Singapore.

Balakrishnan, S. (2001). Home Literacy Practices and Perceptions of Indian Families: Case Studies of Four Families in Singapore. Unpublished Doctoral dissertation. Singapore: National Institute of Education.

Barton, B. (2007). Literacy: An introduction to the ecology of written language. MA: Blackwell Publishing. 
Canagarajah, A. S. (2008). Language shift and the family: Questions from the Sri Lankan Tamil diaspora 1. Journal of Sociolinguistics, 12(2), 143-176.

Department of Statistics Singapore. Census of Population 2015 Statistical Release 1: Demographic Characteristics, Education, Language and Religion. Retrieved from http://www.singstat.gov.sg/publications/publicationsandpapers/cop2010/census10_stat_re lease 1

Dornyei, Z. (2007). Research Methods in Applied Linguistics. United Kingdom: Oxford University Press.

Fernandaz, H. (1998). Patterns of Language Use and Perceptions of Ethnic Identity in 3 Generation Catholic Malayalee Families. Unpublished Academic Exercise, Singapore: National Institute of Education.

Gibbons, J., \& Ramirez, E. (2004). Maintaining a minority language: A case study of Hispanic teenagers (Vol. 129). Multilingual Matters.

Heath, S. (1983). Ways with words. Cambridge: Cambridge University Press.

Kang, H. S. (2015). Korean families in America: Their family language policies and homelanguage maintenance. Bilingual Research Journal, 38 (3), 275-291.

Khoo, C. K. (1981). Census of population 1980 Singapore: Release no. 5, Geographic distribution. Singapore: Department of Statistics.

Koh, G.H. (2010). Preparing for school: An ethnographic study of young Chinese children's literacy learning. Unpublished Doctoral dissertation. Singapore: National Institute of Education.

Lau, K. E. (1992). Singapore census of population, 1990: Demographic characteristics (Vol. 2). Singapore: Department of Statistics.

Lee, J. S., \& Wright, W. E. (2014). The rediscovery of heritage and community language education in the United States. Review of Research in Education, 38(1), 137-165.

Malayalam Language Education Society (Singapore). 2015). Retrieved from http://www.malayalam.org.sg

Ministry of Education Singapore. (2015). Mother Tongue Language Policy. Retrieved from http://www.moe.gov.sg/education/admissions/returning-singaporeans/mother-tonguepolicy/ 
Moore, D. L. (1994). "I don't speak my own language”: Ethnicity among the Malayalees of Singapore (Master's dissertation). Portland State University, Oregon.

Naval Base Kerela Library Singapore. Retrieved from http://nbkl.tripod.com/index.html

Pillai, A.D. (2017). Malayalees in Singapore. In Pillai, A.D., Arumugam, P. (2017). From Kerala to Singapore: Voices from the Singapore Malayalee Community. Singapore: Marshall Cavendish Pte. Ltd. Pillai, A. D. \& Arumugam, P. (2017) From Kerala to Singapore: Voices from the Singapore Malayalee Community. Marshall Cavendish Pte. Ltd.

Pillai, A. D. (2010). Singaporean Malayalam: The Presence of a Hybrid Language. Germany: VDM Verlag Dr. Müller.

Pravasi Express. (2015). Retrieved from http://www.pravasiexpress.com

Sevinç, Y. (2016). Language maintenance and shift under pressure: Three generations of the Turkish immigrant community in the Netherlands. International Journal of the Sociology of Language, 2016(242), 81-117.

Singapore Malayalee Association. (2015). Retrieved from http://malayalee.info

Sridhar, S.N. (1995). Language modernization: Structured and sociolinguistic aspects. Sociolinguistics: South Asian Perspectives. New Delhi: Creative Books.

Wray, A. \& Bloomer, A. (2013). Projects in Linguistics and Language Studies. USA: Routledge. Vasnani, B. (2014, Nov 28). Sharing language concerns: Malayalees discuss issues affecting their community. Asiaone Singapore. Retrieved from http://news.asiaone.com/news/singapore/sharing-language-concerns-malayalees-discussissues-affecting-their-community

Wray, A. \& Bloomer, A. (2013). Projects in Linguistics and Language Studies. USA: Routledge. 